Check for updates

Durham DH1 4LS, UK

bignardi_dimarco@yahoo.co.uk Cite this as: BMJ 2021;373:n937 http://dx.doi.org/10.1136/bmj.n937 Published: 12 April 2021
COVID-19 DISSENTERS

\section{Reporting of AstraZeneca studies may have caused vaccine reservations}

\author{
Giuseppe Bignardi retired consultant microbiologist
}

Abbasi asks whether the negativity towards the AstraZeneca vaccine in the European Union is a political hangover from Brexit. ${ }^{1}$ I think the initial reservations were related to the way the results were presented.

Both Pfizer $^{2}$ and Moderna ${ }^{3}$ had clinical trials based on a single protocol resulting in a single publication with good efficacy in all ages. But the initial AstraZeneca publication was based on multiple protocols and, by mistake, a subgroup of patients had been given a reduced first dose and showed greater efficacy. ${ }^{4}$ The researchers initially attributed the higher efficacy to the reduced dose ${ }^{4}$ but later suggested it was due to the increased interval between doses. 5

Neither of these studies provided direct evidence about the efficacy in older people. This is why some European nations initially decided to use this vaccine only in people under 65; the United States did not authorise the AstraZeneca vaccine at all. Only the more recent effectiveness studies ${ }^{6}$ and the release of the American trial data ${ }^{7}$ have provided definitive evidence of efficacy in older people.

The concerns about blood clots involved a non-EU nation (Norway) and resulted in some countries suspending the distribution of the AstraZeneca vaccine for a few days. My impression is that there was a need to respond to concerns raised in the media across Europe. Signals coming from postmarketing surveillance should not be ignored as low frequency adverse events cannot be identified in phase III trials.

The subsequent report from the European Medicines Agency (EMA) concluded that, despite no overall increase in risk of thromboembolic events, the AstraZeneca vaccine could be associated with two rare types. ${ }^{8}$ The number of these cases subsequently increased to $59,{ }^{9}$ and a common pathogenesis ("spontaneous" heparin-induced thrombocytopenia) has been proposed. ${ }^{10}$

The EMA investigation is ongoing: two members of the public are part of the panel. ${ }^{11}$ Comparing putative side effects with their natural occurrence is difficult. If risk factors were identified, they could be used as selective contraindications to this vaccine.

Competing interests: No competing interests

Full response at: https://www.bmj.com/content/372/bmj.n731/rr-2.

1 Abbasi K. Covid-19 dissenters - or the virtue in being less cheerful. BMJ 2021;372:n731doi: 10.1136/bmj.n731.

2 Polack FP, Thomas SJ, Kitchin N, etalC4591001 Clinical Trial Group. Safety and efficacy of the BNT162b2 mRNA covid-19 vaccine. N Engl I Med 2020;383:2603-15. doi: 10.1056/NEJMoa2034577 pmid: 33301246
3 Baden LR, El Sahly HM, Essink B, etalCOVE Study Group. Efficacy and safety of the mRNA-1273 SARS-CoV-2 vaccine. N Engl J Med 2021;384:403-16. doi: 10.1056/NEJMoa2035389 pmid: 33378609

4 Voysey M, Clemens SAC, Madhi SA, etal. Safety and efficacy of the ChAd0x1 nCoV-19 vaccine (AZD1222) against SARS-CoV-2: an interim analysis of four randomised controlled trials in Brazil, South Africa, and the UK. Lancet 2021;397:99-111.

doi: 10.1016/S0140-6736(20)32661-1. pmid: 33306989

5 Voysey M, Costa Clemens SA, Madhi SA, etalOxford COVID Vaccine Trial Group. Single-dose administration and the influence of the timing of the booster dose on immunogenicity and efficacy of ChAdOx1 nCoV-19 (AZD1222) vaccine: a pooled analysis of four randomised trials. Lancet 2021;397:881-91. . doi: 10.1016/S0140-6736(21)00432-3 pmid: 33617777

6 Bernal JL, Andrews N, Gower C, etal. Early effectiveness of covid-19 vaccination with BNT162b2 mRNA vaccine and ChAdOx1 adenovirus vector vaccine on symptomatic disease, hospitalisations and mortality in older adults in England.MedRxiv https://www.medrxiv.org/content/10.1101/2021.03.01.21252652v1

7 AstraZeneca. AZD1222 US phase III trial met primary efficacy endpoint in preventing covid-19 at interim analysis. 22 March 2021. https://www.astrazeneca.com/media-centre/press-releases/2021/astrazeneca-us-vaccinetrial-met-primary-endpoint.html

8 European Medicines Agency. Covid-19 vaccine AstraZeneca: benefits still outweigh the risks despite possible link to rare blood clots with low blood platelets. 18 Mar 2021. https://www.ema.europa.eu/en/news/covid-19vaccine-astrazeneca-benefits-still-outweigh-risks-despite-possible-linkrare-blood-clots

9 Sterzik K. AstraZeneca: What's the deal with thrombosis? https://www.dw.com/en/astrazeneca-whats-the-deal-with-thrombosis/a56901525

10 Greinacher A, Thiele T, Warkentin TE, et al. A prothrombotic thrombocytopenic disorder resembling heparin-induced thrombocytopenia following coronavirus-19 vaccination. https://www.researchsquare.com/article/rs-362354/v1

11 European Medicines Agency. Covid-19 vaccine AstraZeneca-update on ongoing evaluation of blood clot cases. 25 Mar 2021. https://www.ema.europa.eu/en/news/covid-19-vaccine-astrazeneca-updateongoing-evaluation-blood-clot-cases

This article is made freely available for use in accordance with BMJ's website terms and conditions for the duration of the covid-19 pandemic or until otherwise determined by BMJ. You may use, download and print the article for any lawful, non-commercial purpose (including text and data mining) provided that all copyright notices and trade marks are retained. 